\title{
MEMORY EFFECTS IN AN AMS SYSTEM: CATASTROPHE AND RECOVERY
}

\author{
J S VOGEL ${ }^{1}$, J R SOUTHON ${ }^{1}$ and D E NELSON \\ Department of Archaeology, Simon Fraser University, Burnaby, BC V5A 1S6 Canada
}

ABSTRACT. A sample with a ${ }^{14} \mathrm{C}$ concentration estimated to be greater than 30,000 Modern was inadvertently graphitized and measured in an AMS system. No measurable contamination of the cesium sputter ion source was observed. Simple cleaning procedures removed the contamination from the sample preparation system, with the exception of the reaction vessel in which the sample was graphitized. Sample cross-contamination factors were estimated for all of the preparation and measurement procedures.

\section{MEASUREMENTS}

We have begun a program of biochemical tracer experiments by making AMS ${ }^{14} \mathrm{C}$ measurements on synthesized compounds and stock reagents supplied by the biochemistry division of Lawrence Livermore National Laboratory. Cleaned separatory equipment used in previous tracer studies was also tested by processing unlabeled materials and tracer-free carriers. Despite our best efforts to alert our colleagues about the dangers of serious contamination, we unknowingly received a synthesized sample which proved to have an extremely high ${ }^{14} \mathrm{C}$ content. The measurement of this and subsequent samples provided measurements of process memory effects which would be difficult to estimate by other means.

These samples were prepared using our normal procedures (Vogel, Nelson \& Southon 1987; Vogel, Southon \& Nelson 1987). Samples were combusted in individual quartz tubes, with no possibility of cross-contamination. The $\mathrm{CO}_{2}$ was purified in a steel and glass transport line and then graphitized in 1 of 4 steel and quartz reactors. The graphite-oncobalt powder from each sample was pressed into a sample holder using a drill stem. These holders were placed in the ion source together with Modern standards and background materials for measurement in our usual manner. The samples were processed and loaded in order of increasing expected ${ }^{14} \mathrm{C}$ concentration, based on estimates of the submitters, as shown in Table 1. In previous work, this protocol has prevented serious cross-contamination between disparate samples.

We expected maximum ${ }^{14} \mathrm{C}$ concentrations of a few times Modern, and we have measured such levels before without damage. However, one sample contained "catastrophic" levels of ${ }^{14} \mathrm{C}$. The count rate from this sample grossly overloaded the data acquisition system (dead time was $65-75 \%$ ), but enough data was obtained to estimate its ${ }^{14} \mathrm{C}$ concentration at greater than 30,000 Modern. It was immediately clear that the high ${ }^{14} \mathrm{C}$ concentrations found in other samples (2-40 Modern) were associated with the processing of this sample and that we could use the data to understand memory and cross-contamination levels in our system. The possible contamination paths were not unique, however, and only upper limits could be derived for some processes.

\section{CONTAMINATION LEVELS}

The 30,000 Modern material had been expected to be low in ${ }^{14} \mathrm{C}$ and was the first of the series to be processed. The sample which immediately followed it through our gas transport (C3626 in Table 1) had a ${ }^{14} \mathrm{C}$ level that could not be fully understood. It may have been contaminated by remnants of the preceding "hot" sample in several steps of our preparation, or it may have had a high ${ }^{14} \mathrm{C}$ concentration from the biochemical preparation process. However, the $\mathrm{CO}_{2}$ exchanged between these successively transported samples was less than $1.4 \%$, assuming that all excess ${ }^{14} \mathrm{C}$ in this sample was due to the transport. Whenever it is not in use, the transport tubing is filled with water vapor to desorb $\mathrm{CO}_{2}$ from the surfaces. This procedure reduced the "hot" $\mathrm{CO}_{2}$ exchanged with the next set of samples to a maximum of 53ppm, as shown by the final ${ }^{14} \mathrm{C}$ concentration in sample C3656. The sample (C3657) subsequently graphitized in the same reactor as the "hot" sample may have been

' Present address: Center for Accelerator Mass Spectrometry, Lawrence Livermore National Laboratory Livermore, California 94550 
TABLE 1

Initial and final measured ${ }^{14} \mathrm{C}$ concentrations for samples processed after the graphitization of a 30,000 modern sample, listed in order of gas transport and graphite pressing

\begin{tabular}{|c|c|c|c|c|c|c|}
\hline \multirow{2}{*}{$\begin{array}{l}\text { Sample } \\
\text { no. }\end{array}$} & \multirow[t]{2}{*}{ Material* } & \multirow{2}{*}{$\begin{array}{l}\text { Reactor } \\
\text { no. }\end{array}$} & \multirow{2}{*}{$\begin{array}{l}\text { Sample } \\
\text { size }(\mu \mathrm{g})\end{array}$} & \multicolumn{3}{|c|}{${ }^{14} \mathrm{C}$ concentrations (pMC) } \\
\hline & & & & Initial & Final & Expected \\
\hline C3627 & Synth chem & 2 & 565 & $>3 \times 10^{6}$ & --- & $10-100$ \\
\hline \multirow[t]{2}{*}{ C 3626} & HPLC solvent & 1 & 190 & 4190 & 4190 & $10-?$ \\
\hline & & \multicolumn{5}{|c|}{ Water vapor cleaning of gas transport } \\
\hline C3656 & Protein 1 & 1 & 780 & 1670 & 210 & $50-?$ \\
\hline C3657 & Protein 2 & 2 & 790 & 270 & 165 & $50-?$ \\
\hline C3658 & Protein 3 & 3 & 870 & 65 & 54 & $50-?$ \\
\hline \multirow[t]{2}{*}{ C3659 } & Protein 4 & 4 & 1260 & 76 & 58 & $50-?$ \\
\hline & & \multicolumn{5}{|c|}{ Gas transport and graphitizers cleaned } \\
\hline C3662 & Axel wood & 1 & 1000 & --- & 0.4 & 0.4 \\
\hline $\mathrm{C} 3663$ & Axel wood & $2 * *$ & 1240 & --- & 4.0 & 0.4 \\
\hline C3665 & Axel wood & 3 & 1250 & -- & 0.4 & 0.4 \\
\hline \multirow[t]{2}{*}{ C3664 } & Axel wood & $4 * *$ & 1400 & $\cdots$ & 1.0 & 0.4 \\
\hline & & \multicolumn{5}{|c|}{ Original reactors \#2 and \#4 rebuilt } \\
\hline C3666 & Axel wood & 2 & 1050 & --- & 3.9 & 0.4 \\
\hline C3667 & Axel wood & 3 & 1030 & 0.7 & --- & 0.4 \\
\hline C3668 & Axel wood & 4 & 840 & 0.7 & -- & 0.4 \\
\hline
\end{tabular}

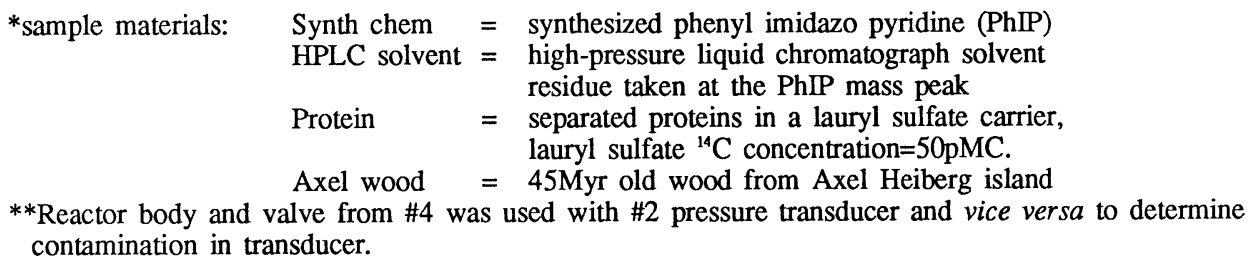

primarily contaminated in transport or in pressing, but its final concentration indicated a maximum possible memory of $40 \mathrm{ppm}$ occurred in the graphitization of the $\mathrm{CO}_{2}$.

Pressing graphite into holders with a drill stem can leave a contaminant on the graphite surface from the preceding sample, even after cleaning the stem with emery paper. We normally sputter this away before final measurements are taken. The six biochemical samples were pressed with the same drill stem, which was then discarded. The measurements of the graphite surfaces ("Initial ${ }^{14} \mathrm{C}$ " in Table 1) showed that up to $1.4 \%$ of the 30,000 Modern sample were transferred to the next sample surface. Moreover, nanogram quantities of the 30,000 Modern sample were transferred to the surfaces of the two succeeding samples despite the abrasion of the tip before pressing each sample.

The 30,000 Modern sample had been sputtered in the ion source for perhaps 10 seconds during positioning and measurement. A background sample was then immediately measured to check for cross-contamination in the ion source. The result was higher (by ca $0.1 \mathrm{pMC})$ than the previous measurements of this material $(0.3-0.4 \mathrm{pMC})$, but other background samples showed no evidence of contamination. We also measured a machine background of $0.05 \mathrm{pMC}$ using geological graphite only a few hours later. Assuming that the inital increase of $0.1 \mathrm{pMC}$ was due to cross-contamination and that this contamination would scale as the sputtering time, the memory effect of our ion source from a typical sample (run for $100-300$ seconds) is less than $1 \mathrm{ppm}$. 
When we realized what had happened, we dismantled the entire graphitization apparatus and ultrasonically cleaned it with detergent for 12 hours. All parts were rinsed in water, dehydrated with a methanol rinse and baked in a vacuum oven at $200^{\circ} \mathrm{C}$ for 3 hours. The complete transport system, including the O-ring seals, was retained. The cold fingers, quartz tubes and all O-ring seals on the reactors were discarded. The pressure transducers were syringed with $0.1 \mathrm{~N} \mathrm{HCl}$ and deionized water. Several background samples were processed through each reactor and no excess ${ }^{14} \mathrm{C}$ was found, except from the reactor in which the 30,000 Modern material had been graphitized (Table 1). Approximately 1.5ppm (1.5ng) of the material appeared in two successive background samples. The transducer was identified as contributing most of the contamination, but the whole reactor was discarded. The reactor which processed the 40 Modern material was retained without detriment. Sixteen different coal samples were graphitized 12 days after this incident, and ${ }^{14} \mathrm{C}$ concentrations of $0.14-0.19 \mathrm{pMC}$ were found in samples prepared in each of the 4 reactors (including a new reactor 2 ).

\section{CONCLUSION}

This experience has provided some useful lessons about cross-contamination in AMS ${ }^{14} \mathrm{C}$ laboratories. A single purification and graphitization apparatus can be used for samples having ${ }^{14} \mathrm{C}$ concentrations from 50 Modern down to $0.2 \mathrm{pMC}$, albeit with some care. However, it would be best to have separate systems for such disparate samples, or to use a sealed-tube graphitization (Slota \& Taylor 1986) in which the "reactor" is disposable. Clearly, water vapor is a valuable means to minimize cross-contamination in the transport tubing. Reaction vessels can be cleaned effectively, except in an extreme case. New drill stems must be used for pressing especially old or small samples. Our experience with ion source cross-contamination is particularly heartening. However, most source contamination probably arises from re-evaporation or ionization of sputtered neutral atoms deposited on surfaces facing the sample, and the effect could be very different for other source geometries and sample materials. While these results show that a wide range of ${ }^{14} \mathrm{C}$ activities can be accomodated in the same AMS system and that recovery from severe contamination is possible, we certainly do not advocate processing both natural and labeled samples in the same chemical laboratory. The long-term consequences are likely to be disastrous. However, it does seem possible to consider measuring both labeled and natural samples on the same accelerator. This will certainly require careful protocol. Pre-screening of some samples with liquid scintillation counters may be necessary until greater experience in AMS micro-tracing is available.

\section{ACKNOWLEDGMENTS}

We would like to acknowledge the contribution of Robert Taylor, without whom this experiment would not have been possible. We thank the faculty and staff of the McMaster University Tandem Accelerator. This work was funded by NSERC and RIDDL.

\section{REFERENCES}

Slota, PJ, Jr and Taylor, RE 1986 AMS ${ }^{14} \mathrm{C}$ analysis of samples from archaeological contexts: pretreatment and target preparation. University of California AMS conf, Proc. Livermore, Inst Geophysics Planetary Physics.

Vogel, JS, Nelson, DE and Southon, JR $1987{ }^{14} \mathrm{C}$ background levels in an accelerator mass spectrometry system. Radiocarbon 29 (3): 323-333.

Vogel, JS, Southon, JR and Nelson, DE 1987 Catalyst and binder effects in the use of filamentous graphite for AMS. Nuclear Instruments \& Methods B29: 50-56. 